\title{
In vivo slit scanning confocal microscopic observation in a patient with moderate and severe keratoconus: a case report
}

This article was published in the following Dove Press journal:

Clinical Optometry

26 August 2016

Number of times this article has been viewed

\section{Haliza Abdul Mutalib \\ Somnath Ghosh \\ Sharanjeet-Kaur \\ Rituparna Ghoshal}

Optometry and Vision Sciences Programme, Faculty of Health Sciences, University Kebangsaan Malaysia, Kuala Lumpur, Malaysia
Correspondence: Haliza Abdul Mutalib Optometry and Visual Sciences Programme, Faculty of Health Sciences, University Kebangsaan Malaysia, Jalan Raja Muda Abdul Aziz, 50300 Kuala Lumpur, Malaysia

Tel +60 392897495

Fax +60326910488

Email halizamutalib@ukm.edu.my
Abstract: A 22-year-old Indian female was referred to $\mathrm{Sg}$ Buloh hospital with the diagnosis of bilateral keratoconus. On examination, slit lamp biomicroscopy and corneal topography revealed stage 3 keratoconus in the right eye and stage 2 keratoconus in the left eye. Corneal cell morphology in both eyes was evaluated using confocal microscope. In qualitative observation, almost all corneal layers in right eye except endothelium were partially or completely obscured by haze. Additionally, morphological alterations, such as elongation of keratocyte nuclei and cluster of cells, and dark bands in the anterior stroma were observed in right eye. In the left eye, the amount of haze was less, allowing better visibility of the corneal layers compared with the right eye. The dark bands were evident in the posterior stroma. Quantitative analysis showed that anterior and posterior stromal keratocyte density and endothelium cell density were relatively low in the right eye $\left(834.0,700.5\right.$, and 2,133 cells $/ \mathrm{mm}^{2}$, respectively) compared with the left eye $\left(934.1,750.6\right.$, and 2,361 cells $/ \mathrm{mm}^{2}$, respectively). In this case, the right eye, exhibiting stage 3 keratoconus, showed more morphological alteration, particularly in the anterior stroma compared with the left eye with stage 2 keratoconus. Increased severity of the disease can explain these differences in corneal cell morphology.

Keywords: confocal microscopy, keratoconus, cornea, stromal haze, striae, keratocyte

\section{Introduction}

Keratoconus is a progressive disease that adversely affects the corneal cell morphology. ${ }^{1}$ The cellular alterations in keratoconus may vary based on the severity of the disease. ${ }^{2}$ However, the morphological changes in keratoconic cornea at different stages of keratoconus are rarely being observed. Confocal microscope plays a key role in evaluating the cellular morphology changes in keratoconic cornea. ${ }^{3-5}$ The following case involves a patient with stage 3 keratoconus in the right eye and stage 2 keratoconus in the left eye, assessed with an in vivo slit scanning confocal microscope.

\section{Case report}

A 22-year-old Indian female was referred to Sg Buloh hospital with complaints of blurred vision in both eyes with spectacles and eye itchiness, which was more evident in the right eye. The patient had no history of any systemic disease, ocular infection, trauma, or ocular surgery. There was no family history of keratoconus. On examination, the best corrected visual acuity was $6 / 60$ in the right eye and 6/9 in the left eye on Snellen visual acuity chart. The subjective refraction in the right and left eyes was -5.00 diopter spherical with -9.00 diopter cylindrical at $10^{\circ}$ and -3.00 diopter spherical 
with -6.00 diopter cylindrical at $180^{\circ}$, respectively. Slit lamp biomicroscopy examination revealed typical features of keratoconus in both eyes, including corneal ectasia, Flesher ring, prominent corneal nerves, Munson's sign, and Vogt's straie. Ocular allergy or infection was not observed during slit lamp biomicroscopy in both eyes. Corneal topography (Pentacam, Oculus, Optikgerate GmBH, Wetzlar, Germany) confirmed the presence of keratoconus in both eyes. Central and paracentral steepening of the cornea was observed in corneal topography (Figure 1). The simulated keratometric readings, obtained with corneal topography, were K1/K2=57.5 D@12.2/66.8 D @ 102.2 and K1/K2=48.3 D@175.6/54.30 D@85.6 in the right and left eyes, respectively. Induced astigmatism detected by the corneal topography was 9.40 and $6.00 \mathrm{D}$ in the right eye and left, respectively. Corneal thickness was 394 and 438 $\mu \mathrm{m}$ in the right and left eyes, respectively, as measured with corneal topographer. The severity of the keratoconus of the patient was graded as stage 3 in the right eye and stage 2 in the left eye based on the Amsler-Krumeich classification. ${ }^{6}$

In vivo slit scanning confocal microscopy (ConfoScan4, Nidek Technologies Srl, Albignasego, Italy), was carried out to evaluate the corneal cell morphology. The nonaplanatic water immersion $40 \times$ objective lens with a numerical aperture of 0.75 and corneal full thickness scan were used in the study. Standard operative procedure was strictly followed to carry out the confocal microscopy. Throughout the examination, a total of 350 images of all corneal layers were captured in each eye. The best three images of each corneal layer were considered for qualitative and quantitative investigation. In qualitative analysis, stromal haze was analyzed based on the grading scale designed by Hollingsworth et al in $2005 .^{7}$ The grading scale described the level of haze and hyperreflectivity of corneal stroma viewed through confocal microscope. Quantitative analysis was performed in semiautomated method using Nidek Advanced Visual Information System (NAVIS) software to analyze the cell area and density of anterior and posterior stroma in a fixed frame of $0.06 \mathrm{~mm}^{2}$. The cells were counted manually using the "L" method. In this method, cells within the fixed frame along with any incomplete cells on the left side and bottom border of each frame were counted, while cells that were located partly on the right side and top border of the frame were not counted. The anterior stroma was considered to be the first image seen immediately after Bowman's membrane, and the posterior stroma was considered to be the keratocyte nuclei images seen before the endothelium. The endothelial cell density and area were analyzed in an automated method by using NAVIS software (Nidek Technologies Srl), which also analyzed the polymegathism and pleomorphism.

\section{Qualitative observation}

In the right eye, images of superficial, wing, and basal epithelial cells were captured with poor visibility. It was also difficult to distinguish Bowman's membrane from anterior stromal layer. Stromal keratocyte nuclei and nerve fibers were found in Bowman's plane (Figure 2). The anterior stroma exhibited grade 2 haze with the irregularities in the shape and size of keratocyte nuclei. Overall, 40\% keratocyte nuclei appeared as thin and elongated compared with keratocyte nuclei viewed in posterior stroma (Figure 3). The average diameter of the keratocyte nuclei was observed as 37.64 and $32.62 \mu \mathrm{m}$ in anterior and posterior stromata,

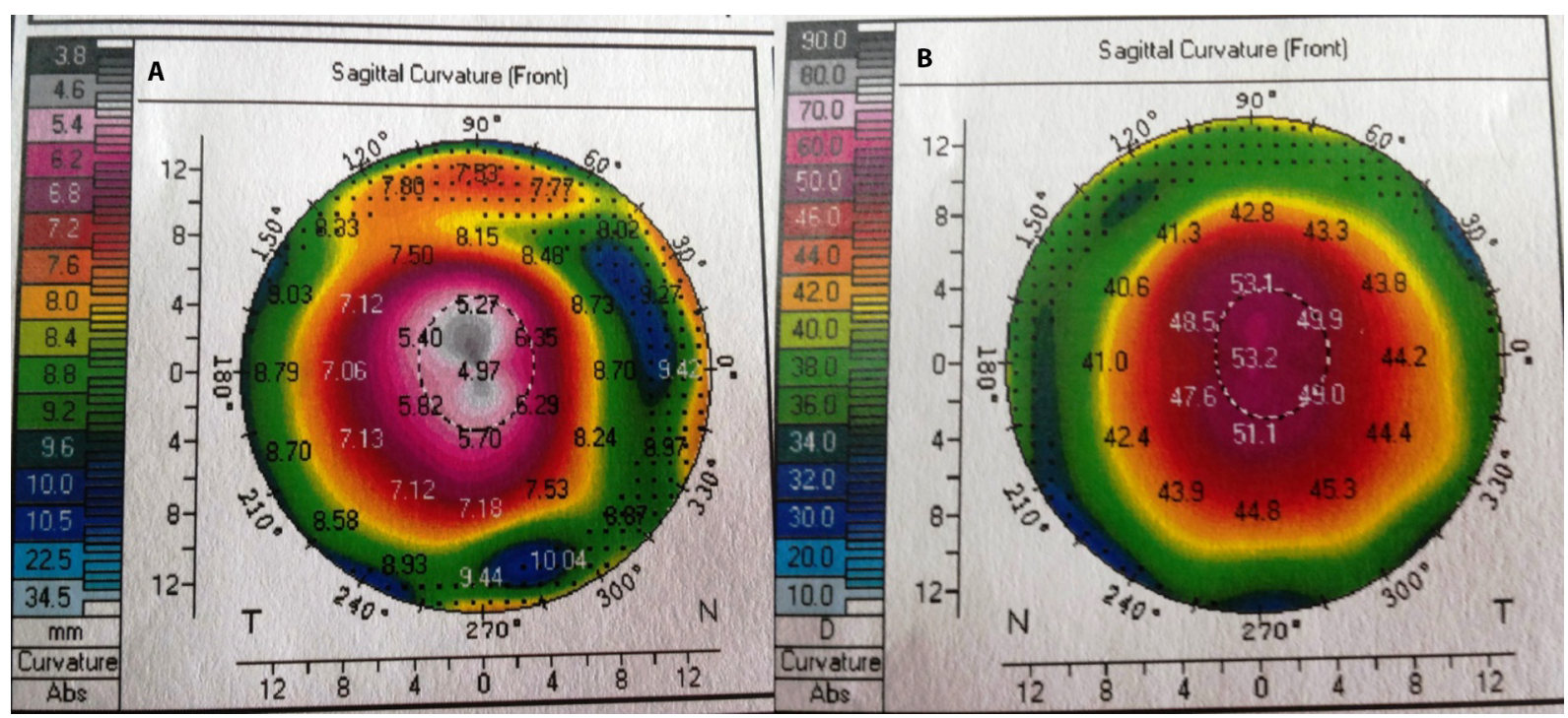

Figure I Corneal topographic curvature map of the right (A) and (B) left eyes. 
respectively. A thick, dense, bright artifact was observed in anterior stroma, which looked like a cluster of cells (Figure 4). Thin, short, and discontinuous dark bands (striae) were observed in anterior stroma (Figure 5). The posterior stroma exhibited grade 1 haze without any morphological alteration. This case report was approved by the ethics committee of Universiti Kebangsaan Malaysia. Written informed consent was provided by the patient.

In the left eye, superficial and basal cells were partially visible without any definite cell borders and nuclei. However, wing cells were not visible. Bowman's membrane was visible as amorphous layer along with vertically oriented nerves with branches. Anterior stroma exhibited grade 1 haze compared with posterior stroma with no (grade 0 ) haze. No alteration in the shape and size of keratocyte nuclei was observed in anterior stroma. Thick, continuous dark bands were seen in posterior stroma (Figure 6).

\section{Quantitative observation}

The nerve fiber density was less in the right eye (14 fibers $/ \mathrm{mm}^{2}$ ) compared with the left eye ( 21 fibers $/ \mathrm{mm}^{2}$ ). The keratocyte density of anterior and posterior stroma was less in the right eye (834.0 and 700.5 cells $/ \mathrm{mm}^{2}$, respectively) compared with the left eye (934.1 and 750.6 cells $/ \mathrm{mm}^{2}$, respectively). The endothelial cell density was also less in the right eye $\left(2,133\right.$ cells $\left./ \mathrm{mm}^{2}\right)$ compared with the left eye $\left(2,361\right.$ cells $\left./ \mathrm{mm}^{2}\right)$. The mean cell area of anterior stroma, posterior stroma, and endothelium was also different in the right from left eye, as shown in Table 1. Polymegathism and pleomorphism were $45.1 \%$ and $38.9 \%$ in the right eye and $32.3 \%$ and $53 \%$ in the left eye, respectively.

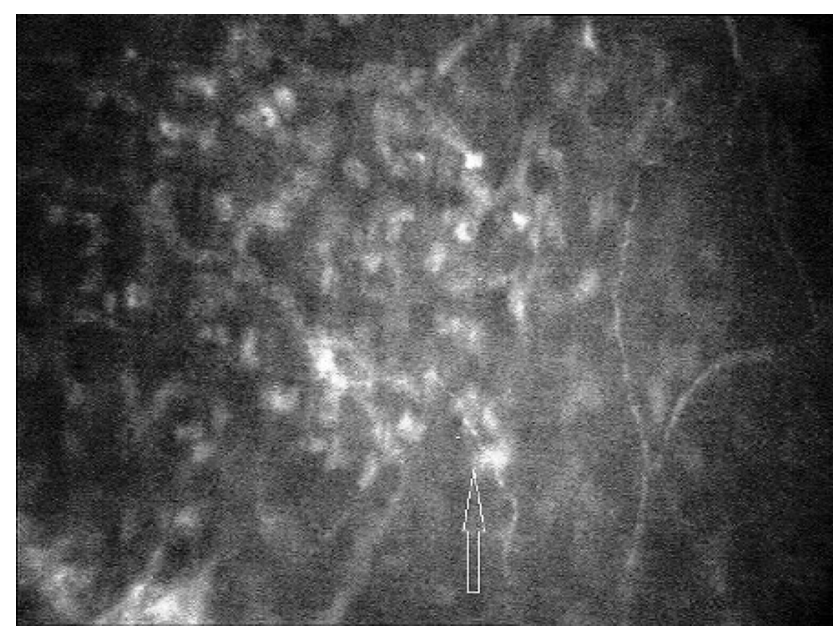

Figure 2 Stromal keratocyte nuclei (arrow) and nerve fibers observed in Bowman's plane of the right eye in stage 3 keratoconus. Magnification $500 \times$ with $40 \times$ objective lens.

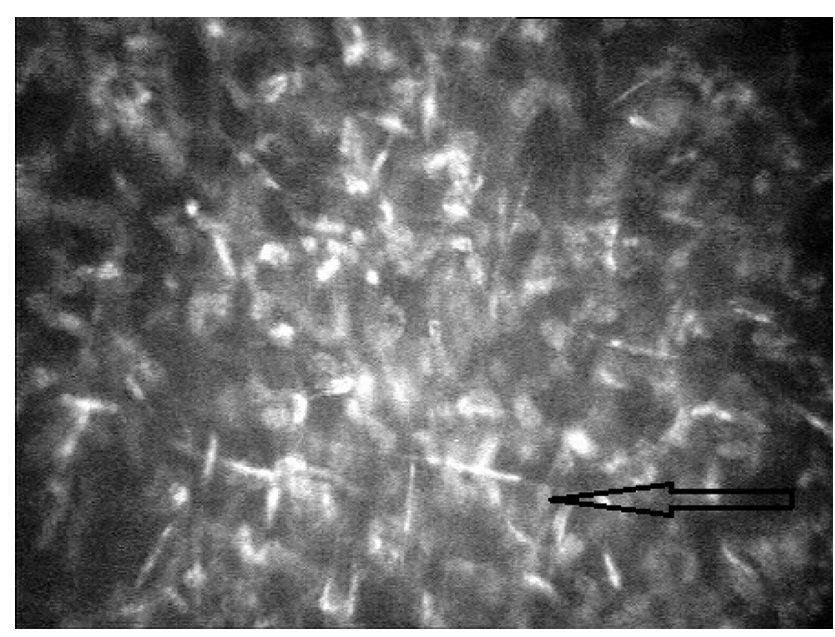

Figure 3 Elongated keratocyte nuclei (arrow) observed in anterior stroma of the right eye in stage 3 keratoconus. Magnification $500 \times$ with $40 \times$ objective lens.

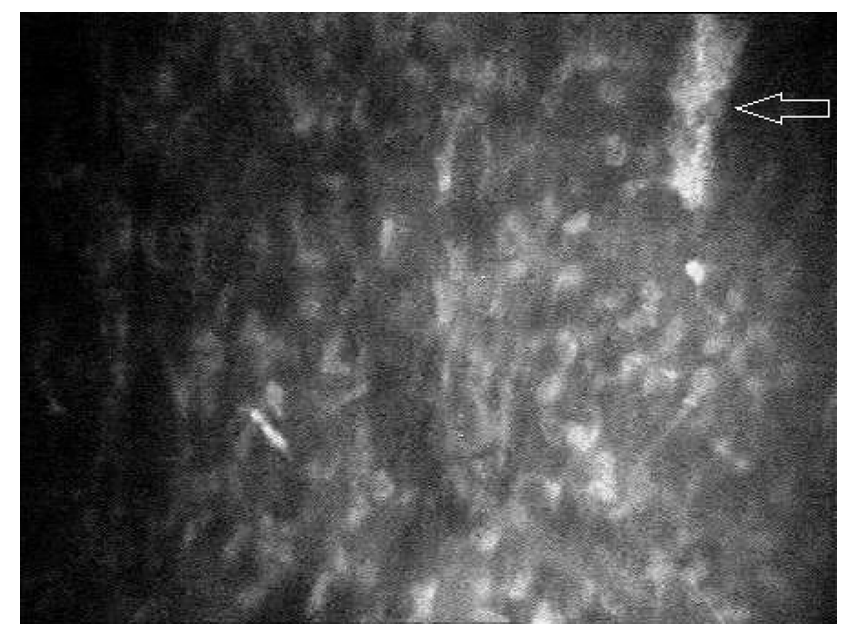

Figure 4 Cluster of cells (arrow) observed in anterior stroma of the right eye in stage 3 keratoconus. Magnification $500 \times$ with $40 \times$ objective lens.

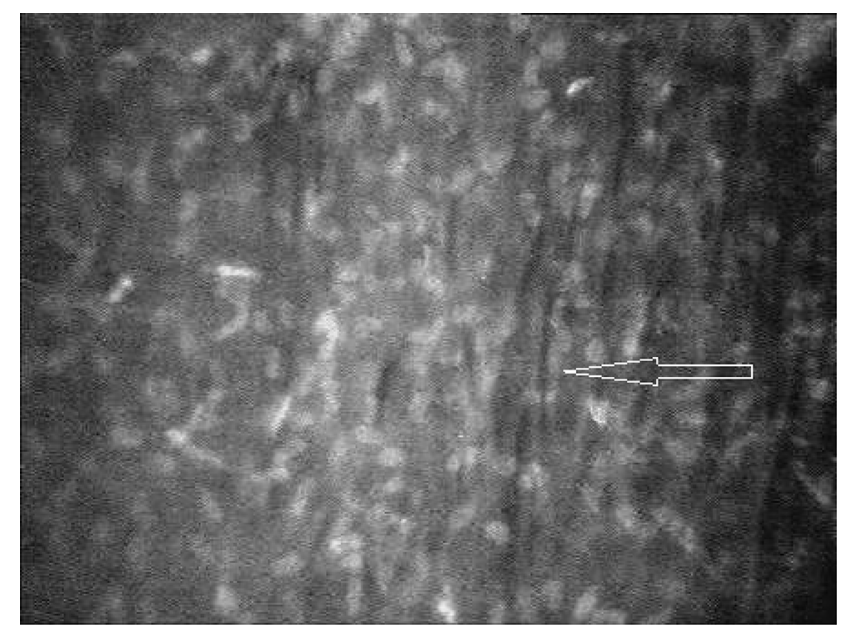

Figure 5 Thin dark bands (arrow) were observed in anterior stroma of the right eye in stage 3 keratoconus. Magnification $500 \times$ with $40 \times$ objective lens. 


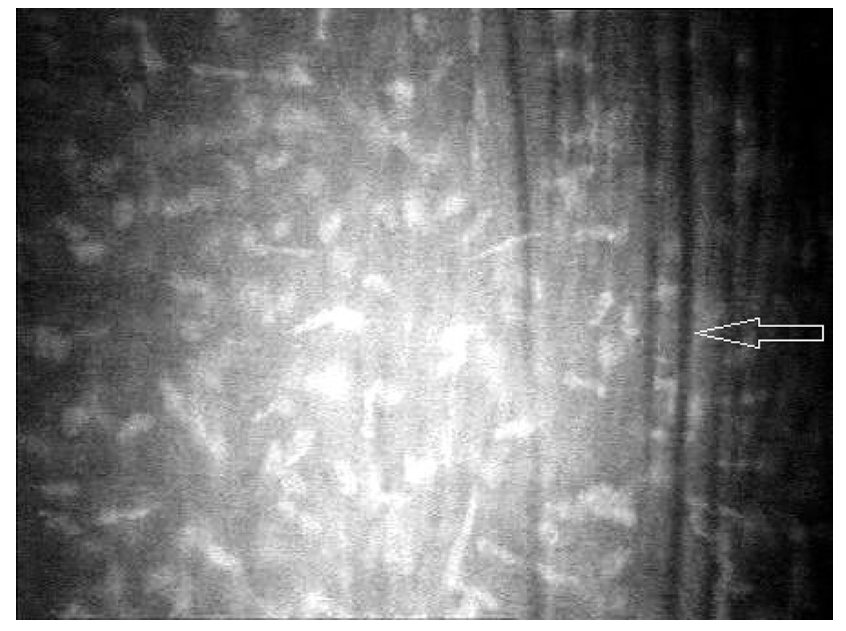

Figure 6 Thick dark bands (arrow) were observed in posterior stroma of the left eye in stage 2 keratoconus. Magnification 500x with 40x objective lens.

\section{Discussion}

The introduction of in vivo confocal microscope has made it possible to study the corneal cellular structures in living corneas in real time facilitating the detailed observation of different corneal pathologies. Research has established that corneal morphology in keratoconus varies significantly from normal healthy corneas. ${ }^{4,5,7,8}$ However, comparison of qualitative and quantitative data between different stages of keratoconus is not yet well documented in literature. In this case report, the corneal cellular alteration observed in the patient exhibited stage 3 keratoconus in the right eye and stage 2 keratoconus in the left eye.

Cellular morphology of all corneal layers in a healthy eye is seen with clarity through confocal microscope. ${ }^{9}$ In contrast, in this patient, different amounts of noticeable haze were found in all corneal layers except endothelium of both corneas. This resulted in poor visibility of the layers. Especially, the three epithelium layers of both eyes were more or less obscured by haze. In keratoconic corneas, loss of transparency (appeared as haze) could be because of disorganization and loss of collagen fibrils. ${ }^{5}$ Altered activities of proteolytic enzymes and irregular regular distribution and lower number of keratocyte are thought to be the factors causing alteration in regular arrangement of collagen fibers in keratoconic cornea. ${ }^{8,10,11}$ Nevertheless, the amount of haze was more in the right eye compared with the left eye that led to difficulty in image analysis. Increased severity of the disease can explain more haze and poor image quality seen in the right eye. However, Hollingsworth et al did not find any relationship between haze in stromal layer and severity of keratoconus. ${ }^{7}$

In the right eye, morphological changes, such as visibility of nerves and stromal keratocyte in Bowman's plane, were
Table I Comparison of cell density and cell area of the right eye with stage 3 and the left eye with stage 2 keratoconus

\begin{tabular}{|c|c|c|}
\hline Corneal layers & Right eye & Left eye \\
\hline $\begin{array}{l}\text { Anterior stroma keratocyte cell density } \\
\left(\text { cells } / \mathrm{mm}^{2}\right)\end{array}$ & 834.0 & 934.1 \\
\hline Anterior stroma cell area $\left(\mu \mathrm{m}^{2}\right)$ & I,199.I & $1,070.6$ \\
\hline $\begin{array}{l}\text { Posterior stroma keratocyte cell density } \\
\left(\text { cells } / \mathrm{mm}^{2}\right)\end{array}$ & 700.5 & 750.6 \\
\hline Posterior stroma cell area $\left(\mu \mathrm{m}^{2}\right)$ & $\mathrm{I}, 427.5$ & $1,332.3$ \\
\hline Endothelial cell density (cells/mm²) & 2,133 & 2,361 \\
\hline Endothelial cell area $\left(\mu \mathrm{m}^{2}\right)$ & 473.1 & 423.6 \\
\hline
\end{tabular}

observed. Previous studies also reported a varying amount of abnormality in the Bowman's layer of different ketaroconic eyes. ${ }^{7,12,13}$ Efron et al has documented a similar finding as "split field" view in Bowman's layer in patients with severe keratoconus. ${ }^{3}$ Fragmentation and breaks in Bowman's layer in the later stage of keratoconus could explain the presence of nerves and keratocyte at Bowman's plane. However, Bowman's layer was visible as an amorphous layer in the left eye with stage 2 keratoconus. Bowman's layer in normal cornea is also seen as an amorphous layer. ${ }^{9}$

Additional morphological alterations, such as thinning, elongation, and hyperreflectivity of anterior stromal keratocyte nuclei, and cluster of cells were also observed in the right eye. Previous studies documented hyperreflectivity and haze of anterior stroma with irregularly arranged keratocyte nuclei. ${ }^{5,7,13,14}$ However, only one study has reported elongation and increased brightness of keratocyte nuclei in anterior stroma. ${ }^{5}$ However, in normal cornea, regularly arranged stromal keratocyte nuclei are seen as round or cigar shaped. ${ }^{9}$ The reason behind the elongation of keratocyte seen is not yet completely understood. However, Maurice has stated that the nonuniform distribution of proteoglycan in stroma may have a link in the shape change of keratocyte..$^{15}$ The thick dense bright artifact observed in the right eye could be the gathering of fibroblastic cells or keratocyte cells. ${ }^{16,17}$ However, no study reported a similar finding. Posterior stroma in keratoconus often exhibits Vogt's striae. Abnormal parting of collagen fibrils is thought to be the reason of the stromal striae seen. ${ }^{713-15}$ Similarly, here in this case, the left eye with stage 2 keratoconus demonstrated a dark band in posterior stroma. However, dark bands were also observed in anterior stroma of the right eye with stage 3 keratoconus. Uçakhan et al also reported Vogt's striae in anterior stroma of keratoconic eyes with moderate and severe keratoconus. ${ }^{5}$ A previous study has also related the alteration of collagen fibrils in stromal lamellae with the progression of the disease. ${ }^{18}$ 
The average keratocyte density in anterior and posterior stroma in keratoconus is lower compared with normal cornea. ${ }^{3-5}$ In the present study, anterior and posterior stromal keratocyte density was less in the right eye compared with left eye. This loss of keratocyte density could be explained by the increased apoptosis of keratocyte in the more severe stage of the disease. Erie et al and Uçakhan et al also suggested that the loss of keratocyte in keratoconus can be associated with disease severity. ${ }^{4,5}$ Similarly, lower density of nerve fiber and endothelial cells in right eye compared with left eye could be related to the increased severity of keratoconus. ${ }^{19}$ In the present study, polymegathism and pleomorphism were different in the right from the left eye. However, normal cornea reveals hexagonal endothelial cells without any polymegathism and pleomorphism. ${ }^{9}$ Studies have suggested that degenerative and ectatic changes in keratoconus may be the reasons behind the alteration in hexagonality of the endothelial cells..$^{20,21}$

\section{Recommendation}

Confocal microscope has the potential to play a major role in the evaluation and long-term monitoring of corneal microstructure in keratoconus patients. In the above discussed case, corneal cell morphology of right and left eyes was noticeably different. The right eye exhibiting stage 3 keratoconus showed more cellular alteration particularly in the anterior stroma. Increased severity of the disease can explain these differences in cell morphology. The limitation of the present study was the inability to analyze corneal epithelium due the poor image quality. In conclusion, we recommend further investigation of corneal cell morphology in different stages of keratoconus with a good number of patients to understand the cellular alterations in different stages of keratoconus.

\section{Disclosure}

The authors report no conflicts of interest in this work.

\section{References}

1. Romero-Jiménez M, Santodomingo-Rubido J, Wolffsohn JS. Keratoconus: a review. Contact Lens Anterior Eye. 2010;33(4):157-166.

2. Rabinowitz Y. Keratoconus. Surv Ophthalmol. 1998;42(4):297-319.
3. Efron N, Hollingsworth JG. New perspectives on keratoconus as revealed by corneal confocal microscopy. Clin Exp Optom. 2008;91(1): 34-55.

4. Erie J, Patel S, McLaren J, Nau CB, Hodge DO, Bourne WM. Keratocyte density in keratoconus. A confocal microscopy study. Am JOphthalmol. 2002;13(5):689-695.

5. Uçakhan OO, Kanpolat A, Ylmaz N, Ozkan M. In vivo confocal microscopy findings in keratoconus. Eye Contact Lens. 2006;32(4): 183-191.

6. Ishii R, Kamiya K, Igarashi A, Shimizu K, Utsumi Y, Kumanomido T. Correlation of corneal elevation with severity of keratoconus by means of anterior and posterior topographic analysis. Cornea. 2012; 31(3):253-258.

7. Hollingsworth JG, Efron N, Tullo AB. In vivo corneal confocal microscopy in keratoconus. Ophthalmic Physiol Opt. 2005;25(3):254-260.

8. Weed KH, MacEwen CJ, Cox A, McGhee CNJ. Quantitative analysis of corneal microstructure in keratoconus utilising in vivo confocal microscopy. Eye (Lond). 2007;21(5):614-623.

9. Efron N. Contact lens-induced changes in the anterior eye as observed in vivo with the confocal microscope. Prog Retin Eye Res. 2007;26(4): 398-436.

10. MackiewiczZ, Määttä M, Stenman M, Konttinen L, Tervo T, KonttinenYT. Collagenolytic proteinases in keratoconus. Cornea. 2006;25(5): 603-610.

11. Sawaguchi S, Yue BY, Chang I, Sugar J, Robin J. Proteoglycan molecules in keratoconus corneas. Investig Ophthalmol Vis Sci. 1991; 32(6):1846-1853.

12. Hollingsworth JG, Efron N. Observations of banding patterns (Vogt striae) in keratoconus: a confocal microscopy study. Cornea. 2005;24(2):162-166.

13. Hollingsworth JG, Bonshek RE, Efron N. Correlation of the appearance of the keratoconic cornea in vivo by confocal microscopy and in vitro by light microscopy. Cornea. 2005;24(4):397-405.

14. Somodi S, Hahnel C, Slowik C, Richter A, Weiss DG, Guthoff R. Confocal in vivo microscopy and confocal laser-scanning fluorescence microscopy in keratoconus. Ger J Ophthalmol. 1996;5(6):518-525.

15. Maurice DM. The cornea and sclera. In: Davson H, editor. The Eye. New York: Academic Press; 1984.

16. Sawaguchi S, Fukuchi T, Abe H, Kaiya T, Sugar J, Yue BY. Threedimensional scanning electron microscopic study of keratoconus corneas. Arch Ophthalmol. 1998;116(1):62-68.

17. Scroggs MW, Proia AD. Histopathological variation in keratoconus. Cornea. 1992;11(6):553-559.

18. Hayes S, Boote C, Tuft SJ, Quantock AJ, Meek KM. A study of corneal thickness, shape and collagen organisation in keratoconus using videokeratography and X-ray scattering techniques. Exp Eye Res. 2007; 84(3):423-434.

19. Bitirgen G, Ozkagnici A, Bozkurt B, Malik RA. In vivo corneal confocal microscopic analysis in patients with keratoconus. Int J Ophthalmol. 2015;8(3):534-539.

20. Chi HH, Katzin HM, Teng CC. Histopathology of keratoconus. Am J Ophthalmol. 1956;42:847-860.

21. Sturbaum CW, Peiffer RL. Pathology of corneal endothelium in keratoconus. Ophthalmologica. 1993;206:192-208.

\section{Clinical Optometry}

\section{Publish your work in this journal}

Clinical Optometry is an international, peer-reviewed, open access journa publishing original research, basic science, clinical and epidemiological studies, reviews and evaluations on clinical optometry. All aspects of patient care are addressed within the journal as well as the practice of optometry including economic and business analyses. Basic and clinical
Dovepress

research papers are published that cover all aspects of optics, refraction and its application to the theory and practice of optometry. The manuscript management system is completely online and includes a very quick and fair peer-review system, which is all easy to use. Visit http://www.dovepress. com/testimonials.php to read real quotes from published authors. 